\title{
The future of road transport in Europe. Environmental implications of automated, connected and low-carbon mobility
}

ARTICLE INFO

Received: 25 August 2021 Revised: 25 August 2021

Accepted: 25 August 2021

Available online: 31 August 2021
The increasing efficiency of the transport system during the last 100 years has fuelled and sustained the unprecedented economic growth of our society. It has shaped our livestyles and influenced the development of our cities and town. At the same time it has posed several challenges to our world as the provision of transport opportunities has heavily contribuitred to the depletion of natural resources, pollution, greenhouse gas emissions, etc. Road transport in particular has had a major role into this.

Several policies have been introduced during the last 50 years in the attempt to limit the impact of the transport system, but they have been effective only to a certain extent. During the last years, however, new technologies and social trends are promising to disrupt the transport system and make it substantially more efficient and more sustanable. The present paper discusses the possibile environmental impacts of some of the new technologies applied to transport, in particular highlighting how its complexity may jeopardize the possible improvements that the new technologies promise without properly governing their use.

Key words: road transport, connected and automated mobility, electric vehicles, future mobility solutions, social implications

This is an open access article under the CC BY license (http://creativecommons.org/licenses/BY/4.0/)

\section{Introduction}

Transport is one the main pillars of our society. The ubiquitous availability of transport opportunities and the possibility to reach almost any place in the world in a limited amount of time has fueled and sustained globalization and the unprecedented economic growth of the last century. Transport is so intertwined with our economy that also during the lock-downs imposed by the COVID-19 pandemics in Europe, mobility could be reduced only to a certain extent. In Italy, one of the European countries hit most heavily by the pandemics, for example, in spite of the heavy restrictions to the mobility of people, overall mobility never dropped by more than $60 \%$ to ensure the provisions of the essential services [1].

At the same time it has had wider social effects beyond providing seamless and effective mobility. It has created the automobile city, transforming the time-space 'scapes' of the modern urban/suburban dweller as well as the automobile 'subject', together with his desires and performance of status, man/womanhood and power. The development of mass production and consumption economic model has been initiated by the revolution in vehicle production processes (this economic model is also referred to as ism ${ }^{1}$ ). As a result, any substantial changes in the transport system may result in a transition in our economic and social systems. This is especially true in Europe where sectors linked to road transport account for about $15 \%$ of European Gross Value Added and 10\% of European employment [2].

Yet the sector is following an unsustainable pathway. Productivity losses due to delay and congestion account for approximately 1-2\% of EU GDP, not to mention the 26,000 deaths and the 1 million injured on European roads before the COVID-19 pandemics (in 2020 indeed this figures got

\footnotetext{
${ }^{1}$ https://www.britannica.com/topic/Fordism
}

substantially reduced due to the mobility restrictions applied in Europe ${ }^{2}$ ). Road transport is also the main responsible for poor air quality in European cities together with heating and the second source of greenhouse gases in Europe (and the only one among the main sources which is still increasing its contribution). It is therefore clear that achieving the sustainable development goals that our society has defined requires addressing the challenges posed by the transport system as a whole and by road transport in particular [2].

Policy makers thus face the challenge of having to act on a sector to reduce its externalities while at the same time preserving the economic model it sustains. In other terms transport policies have a "bearing on many, often conflicting, interests, as can easily be seen from the heated debates that accompany almost all decisions concerning transportation at all scales" [3].

In this picture it should not be a surprise that high-level strategic actions aimed at regulating road transport usually advocates the deployment of innovative technological solutions that can contribute to achieve both objectives. The recent European Green Deal ${ }^{3}$ and the related EU Strategy on Sustainable and Smart Mobility ${ }^{4}$ adopted by the European Commission are not an exception. Digital solutions (powered by vehicles connectivity and automation and by the shared economy paradigm) together with a transition to low-carbon vehicle technologies (in particular electrification and hydrogen-based technologies) are at the centre of the European vision to make transport smarter and more

\footnotetext{
${ }^{2}$ https://ec.europa.eu/transport/modes/road/news/2021-04-20-roadsafety_en

${ }^{3}$ https://ec.europa.eu/info/strategy/priorities-2019-2024/european-greendeal_en

${ }^{4}$ https://ec.europa.eu/info/law/better-regulation/have-yoursay/initiatives/12438-Sustainable-and-Smart-Mobility-Strategy_en
} 
sustainable. The high level objectives to fundamentally transform mobility and transport are underpinned by ambitious research and innovation programmes. For example, under the 7th Framework Programme for Research (FP7) and the Horizon 2020 Framework Programme for Research and Innovation (H2020) about $€ 3.07$ bn have been invested in research projects on electrification (addressing all transport modes). This includes $€ 1.85$ bn of EU funds and about $€ 1.22$ bn of own contributions by beneficiary organisations [2].

And this is not a sort of political alchemy. As probably never in the past, indeed, the convergence of several new technologies and business models may really succeed to transform a sector which has remained conceptually unchanged for several decades after the mid of the 20th century. Flexible options like electric bikes, scooters and modular automated shuttles may make public transport more accessible by shrinking the 'last mile' to and from our homes or workplaces. Innovation can slash costs and spur demand: full automation cuts out drivers, electrification simplifies production and lowers running costs, while sharing can increase profits by making vehicles work $24 / 7$ and use the road more efficiently.

However, new technologies alone will not spontaneously make our lives better. Transport systems are indeed "internally complex systems, made up of many elements influencing each other both directly and indirectly, often nonlinearly, and with many feedback cycles" [3]. This means that without their integration in a broader policy framework, the eventual impact of the new technologies cannot be easily anticipated and may also worsen today's situation. As an example, early evidence suggests that transport efficiency is not necessarily improving. New mobility solutions such as car sharing, ride sharing and ride-hailing services are making cars even more appealing, thereby luring passengers from public transport which is often perceived as old, dangerous and uncomfortable especially in the context of the COVID-19 pandemic. As a result, several cities, especially in the US, have experienced a significant increase in road congestion. If the introduction of automated vehicles will make car-based transport cheaper and even more comfortable, the situation will deteriorate further.

At the same time, flexible options may remain out of the reach of the more price-sensitive segments of the population unless they are well integrated into the public transport system. Policymakers must act to ensure that new technologies will make future transport cleaner and more equitable than its car-centered present. Left unmanaged, such changes may widen the gaps in our societies.

Given these premises, without the ambition to cover all the possible implications of a disruption in road transport, the present paper would like to bring some example of possible unexpected effects of the complexity in the transportation system, which could offset some of the benefits promised by new technologies. In this context the present paper is organized as follows. In the next chapter an overview of the historical evolution of environmental legislations concerning road transport is provided. Then two examples related to the effect of transport complexity are introduced and finally a possible approach to keep the com- plexity under control is presented before the conclusions of the paper are provided.

\section{Regulating emissions from road transport in Europe}

\section{1. $\mathrm{CO}_{2}$}

As mentioned in the introductory section, transport constitutes one of the main $\mathrm{CO}_{2}$ and pollutant emissions sources in Europe and remains the only sector where greenhouse gas emissions have not reduced since 1990. Road transport accounts for the lion's share of these emissions (Fig 1).

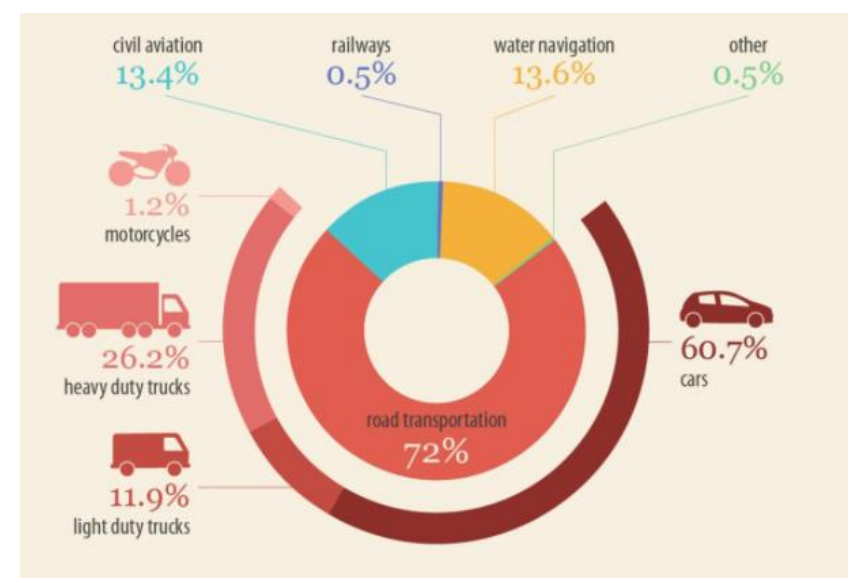

Fig. 1. Transport $\mathrm{CO}_{2}$ emissions in the EU and breakdown by transport mode. Source [5]

The EU has taken several initiatives to improve the situation, particularly focusing on light duty vehicles, already since mid-nineties. Already in 1995 had proposed a voluntary $\mathrm{CO}_{2}$ emissions NEDC-based, sales weighted, target of $120 \mathrm{~g} / \mathrm{km}$ for light duty vehicles effective by 2005 . Eventually this led to the first voluntary commitment by the EU industry to achieve $140 \mathrm{~g} / \mathrm{km}$ by 2008 . The eventual miss of this target triggered the adoption of the first regulated $\mathrm{CO}_{2}$ emissions targets for passenger cars in 2009 , introduced by 2009/443/EU [6]. This included sales weighted, fleet-wide, mass-dependent targets for 2015 of $130 \mathrm{~g} / \mathrm{km}$, to be supplemented by certain off cycle reductions that would be achieved by the adoption of energy saving technologies and practices. The EU later introduced a mandatory target for year 2020 that was set to $95 \mathrm{~g} / \mathrm{km}$ for passenger cars. The targets were linked to penalties ranging between 5 and $95 €$ for each gram of $\mathrm{CO}_{2}$ exceeded per vehicle sold in the EU. In the meantime, the Commission initiated many different actions to curb $\mathrm{CO}_{2}$ emissions from transport on different levels including the certification of $\mathrm{CO}_{2}$ emissions from other vehicle types, deployment of alternative fuels and biofuels, emissions trading systems for the aviation sector and several others.

Up to 2017, the New European Driving Cycle, i.e. the NEDC, was used to certify fuel consumption and $\mathrm{CO}_{2}$ emissions of new light duty vehicles. However, several studies have demonstrated that official NEDC $\mathrm{CO}_{2}$ emission values and fuel consumption figures experienced during real-world driving conditions diverged, with this divergence increasing significantly over time, reaching levels 
close to $30-40 \%$ during the latest years [7]. To compensate for this situation and improve the reliability of the certification procedure, in 2017 EU replaced the NEDC by the Worldwide harmonized Light-duty vehicles Test Procedure, i.e. the WLTP (Regulation EU 2017/1151 [8]), for the typeapproval of new vehicles. In addition to increasing the robustness of the test procedure the WLTP should bridge about half of the divergence between laboratory and realworld $\mathrm{CO}_{2}$ emission figures [9].

Further to this the EU has adopted in 2019 new $\mathrm{CO}_{2}$ targets for light and heavy duty vehicles for years 2025 and 2030 foreseeing substantial $\mathrm{CO}_{2}$ emissions reductions of $37.5 \%$ and $30 \%$ respectively. In parallel the obligation to monitor reduction in real world operating conditions was introduced through the use of on board fuel consumption monitoring systems. As part of the Green Deal for Europe the European Commission has proposed in July 2021 a substantial revision of the post 2020 targets for light duty vehicles to more ambitious targets, while an update to the $\mathrm{HDV} \mathrm{CO}_{2}$ emissions targets is also in preparation as of summer 2021. The aim is to guarantee a $55 \%$ reduction of $\mathrm{CO}_{2}$ emissions in 2030 (1990 as a reference), and carbon neutrality by 2050 .

\subsection{Pollutant emissions}

Transport is known to be one of the main contributors to air pollution especially in urban areas with intense traffic conditions. Since the 70-ies different pieces of legislation have addressed pollutant emissions from vehicles later followed by the introduction of the so called Euro standards. Over the last decades the emission limits have been reduced by more than $90 \%$ compared to Euro 1 for LD and Euro I for HD vehicles standards that entered into force in 1992. Over the years the focus shifted from gaseous pollutants like CO and VOCs to particle emissions that were found to be one of the biggest air quality problems in many areas together with too high ozone levels. The Euro 5 and V led de-facto to the adoption of the best available technology, the particulate filter (DPF), in most of the vehicles equipped with diesel engine. In 2011 a report from the JRC [10]highlighted that real world exhaust emissions of $\mathrm{NO}_{\mathrm{x}}$, in particular for diesel vehicles, were not decreasing as expected due to the introduction of stricter limits. As a consequence, the European Commission established in early 2011 a working group to address real driving emissions. Different measures were taken into consideration but quickly only two options remained on the table, namely the introduction of i) random cycles executed in the lab, or ii) on-road tests carried out with Portable Emission Measurement System (PEMS). The latter approach had been already introduced with the Euro VI standards for the in-service conformity check of the emissions of HD vehicles. Since the PEMS at the time were still bulky and heavy, there were some doubts about the feasibility of on-road test in the case of LD vehicle but other reports from JRC demonstrated that such tests were a viable option [11].

After the Dieselgate outbreak in 2015, the development of the Real Driving Emission (RDE) legislation accelerated and between 2016 and 2018 the new on-road tests were finally introduced in the European emission certification procedure for $\mathrm{LD}$ vehicles. Basically, while the laboratory based test was retained mainly for the $\mathrm{CO}_{2}$ emission certification purpose, the on-road test became the most important one as far as pollutant emissions are concerned.

The new RDE legislation brought immediate benefits as demonstrated by the fact that the gap between the $\mathrm{NO}_{\mathrm{x}}$ emissions measured at the type approval and the values recorded on the road basically disappeared with the new generation of Euro 6 vehicles homologated following the new procedure [12].

In 2019-2020 the development process of the post-Euro 6-VI standards started with the declared objective of defining the ultimate set of provisions to bring pollutant emissions from vehicles to the lowest possible level. A study on the subject was announced by the European Commission and the consortium in charge of the study presented the main findings and the first ideas to the main stakeholders, the Advisory Group on Vehicle Emission Standards (AGVES), in several public meetings.

The proposed approach is based on the following main concepts:

- Pollutant emissions should be controlled under almost all the typical usage conditions of vehicles - this mainly means to extend significantly the boundary conditions under which emissions should be checked and therefore controlled.

- Extending the range of pollutant to be checked by introducing limits for $\mathrm{NH}_{3}, \mathrm{~N}_{2} \mathrm{O}$ and other currently unregulated pollutants (e.g. non-exhaust particle emissions, namely brake wear particle emissions).

- Extending the durability requirements to cover the full useful life of vehicles.

- Align the limits to the strictest in the world.

On these basis, the European Commission is expected to submit an official proposal by the end of 2021.

\section{Implications of transport complexity}

\subsection{Increased energy efficiency of road vehicles}

The previous sections confirm the important role that technology is asked to play by policy in order to reduce the impact of road transport on environment. The Global Climate and Energy Outlook 2018 [13] analysed GHG emissions in transport (not only road) looking at a broad diversification in the fuel mix across modes (electrification, biofuels, hydrogen, natural gas, synthetic fuels) as well as technological fuel-efficiency gains and other operational improvements. The results of the study show that global GHG emissions in transport could be halved between 2015 and 2050 (Fig. 2), contributing to mitigation of global warming to $2^{\circ} \mathrm{C}$ and below by the end of the century. It is worth noticing that in this analysis the growth in mobility does not take into account any possible rebound effect linked to higher energy efficiency or to higher comfort induced by new mobility solutions. In addition the emissions related to the production of "Hydrogen", "Biofuels" and "Electrification" are not taken into account. This latter point is particularly important because especially for greenhouse gases what matters are the emissions generated during the entire vehicle life cycle (LCA) and not only during the vehicle use. On this aspect, many studies have raised concerns especially about batteries, pointing to the fact that the bene- 
fits from batteries tend to be nullified looking at them from an LCA perspective and that instead only fuel cell vehicles (FCEVs) represent a valid solution to reduce emissions from road transport.

A recent study commissioned by the European Commission [14] has instead showed that the above criticisms may hold today in which the complete value chain of Battery Electric Vehicles (BEVs) is not yet fully developed. However taking into account the plausible improvements that will occur in the next years and looking at the 2050 situation, it is possible to expect that BEVs, Gasoline Plugin hybrid vehicles (PHEVs) and FCEVs will all contribute to reduce the impact of road transport on environment if compared to internal combustion engine vehicles (both considering current and future technology). It is worth mentioning that this is valid from a multicriteria perspective since the analysis considered the following dimensions: Global Warming Potential, Cumulative Energy Demand, Photochemical Ozone Creation Potential, Particulate Matter Formation, Human Toxicity Potential, Abiotic Resource Depletion, minerals and metals, Water Scarcity. Adopting an LCA approach should therefore not alter the aforementioned results.

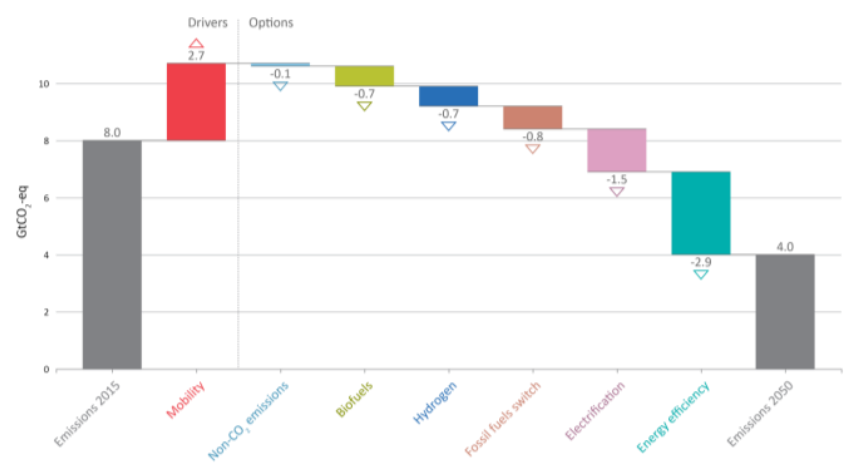

Fig. 2. Transport GHG mitigation options from 2015 to 2050 , central $2^{\circ} \mathrm{C}$ scenario, world, in billion tonnes of $\mathrm{CO}_{2}$ equivalent $\left(\mathrm{GtCO}_{2 \text {-eq }}\right)$. Source: POLES-JRC 2018 (Keramidas et al., 2018)

The effect of a possible rebound in the mobility linked to higher energy efficiency and higher comfort due to connected and automated vehicles and the possible increase in the energy consumption of connected and automated vehicles have instead only marginally been assessed so far.

In general connected and automated vehicles are expected to reduce energy consumption of driving thanks to their capabilities to apply smoother and more efficient operations and to reduce congestion. In reality, recent studies based on empirical data collected from low levels of automation vehicles have showed that they contribute to increase energy consumption by delayed and harsher operations compared to human drivers ([15], [16]). In general it is expected that vehicles with higher level of automation will have more advanced control strategies, also thanks to higher performance sensors which will be able to reduce reaction times and reduce the need for harsh operations. Some studies have however showed that the potential of eco-driving for electric CAVs will not allow to reduce their energy consumption by more than $9 \%$ [18].
For what concerns congestion, it has also been recently showed that for EVs the relationship between road congestion and energy consumption is different than for ICEVs, with energy consumption almost monotonically increasing with the average traffic speed. This means that if CAVs will be able to better use road capacity, and thus to increase the average speed of traffic flow, they may lead to an increase in energy consumption and therefore in induced greenhouse gas emissions.

In reality however, it is highly unlikely that CAVs will be able to solve road congestion. Road traffic is indeed the result of an equilibrium between the demand of mobility and opportunities offered by the transportation system. Road congestion means that the mobility demand is bigger than road capacity so that there is a number of people accepting the discomfort of delays and dense traffic and still use the car to address its mobility demand. If traffic becomes faster, what usually happens is that more people are willing to use the road for their mobility. These people are those who do not accept current congestion levels and that therefore choose alternative options to satisfy their mobility demand. With the increase in road capacity presumably induced by CAVs, road traffic will thus move to a new equilibrium conditions between transport demand and traffic conditions. This means that if CAVs increase their capacity and more vehicles are attracted to the road, CAVs' overall impact on total energy consumption is likely be negative. Along these lines, a recent microeconomic study has shown that the additional travel demand induced by CAVs can generate a rebound effect able to increase the overall energy consumption in road transport by up to $30 \%$ [19]. Similar dynamics may arise from the introduction of new transport options for last-mile freight delivery services (such as drones and automated robots). In spite of their limited size and weight and their potential to take LCVs off the road, drones are forced to go back to their hive due to limitations in weight and range [20], which can lead to higher energy consumption than that of conventional diesel vehicles [21].

Apart from their operations and the latent demand attracted to road transport, an emerging issue related to CAVs is the energy consumption of sensors, computing power and communication that on and off the vehicle will be needed to support their activities. Although still at an early stage, recent estimates have showed that this energy consumption can significantly increase the energy demand of road transport. In particular, it is showed in [22] that under certain assumption, the additional energy consumption required by sensors, V2X communication and back-end systems can range between 300 and $1400 \mathrm{Wh} / \mathrm{km}$ for an average passenger car.

Clearly, to understand the impact that CAVs will have on the energy consumption from road transport it will be very important to carefully monitor the different factors that will contribute to it, and to put in place proper measures to avoid that connectivity and automation may offset the benefits of electrification,

\subsection{Electrification of road vehicles}

In the previous section it is shown that vehicles electrification without considering the possible impact of connec- 
tivity and automation could help addressing some of the externalities related to road transport. In reality also electrification poses some important challenges, in particular for what concerns the use of raw materials.

In line with current EU raw materials policy and SDG objectives, future mobility will have to rely on a sustainable, continuous and adequate supply of raw materials. A sustainable supply means being able to meet the demands from the economic sectors, without compromising natural and social systems. Supply can be assured by materials extracted within the EU (e.g. opening new mines or ramping-up existing ones), by the sustainable supply of materials from non-EU countries, and by the provision of secondary raw materials from recycling waste and products in stock (the so-called urban mining ${ }^{5}$ ).

In addition, access to materials at reasonable prices will be necessary to prevent them from becoming a bottleneck in the development of new technologies and ambitious future mobility scenarios in the EU [23]. Hence, a challenge for future mobility is to ensure a stable supply of materials and a high level of reuse, remanufacturing and recycling to meet the demand arising from new transport technologies and services. Special materials are essential for several key functions and components of future mobility technologies, in particular: batteries (essential for electrification), magnets (for high-efficiency engines), electronics (for connectivity and sharing), sensors (for automation and connectivity), and lightweight structural parts (for electrification and overall for robust and efficient vehicles and infrastructures). Supply risks for mobility concern several materials (e.g. $\mathrm{Co}, \mathrm{B}, \mathrm{In}, \mathrm{Mg}, \mathrm{Pt}, \mathrm{Pd}$, Ta, Sc, V, graphite and rare-earth elements), which have already been identified as 'critical' for the EU. Other materials could become critical in the near future (e.g. Li, Mn, Ni, $\mathrm{Zr}$ ) due to their increased use in new technologies.
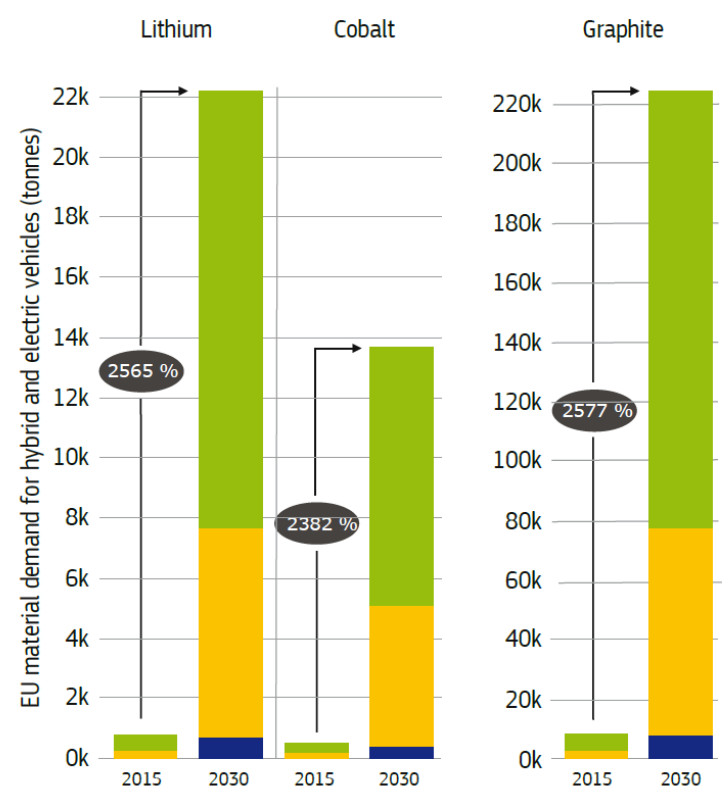

Fig. 3. Demand forecast in the EU for selected critical raw materials for the BEV, PHEV and HEV segments [24]

\footnotetext{
${ }^{5}$ See, for example, the $\mathrm{H} 2020$ project ProSUM:

http://www.prosumproject.eu/
}

The electrification of mobility will redefine, in particular, the market in traction batteries. The demand for lithium, cobalt and graphite is expected to increase exponentially in the coming decades (especially if the current battery technology is maintained). Future demand for several rare-earth elements (e.g. neodymium, praseodymium and dysprosium) will also grow as a result of their use in permanent magnets for electric motors (assuming the adoption of current technologies). Based on 2030 forecasts for the market penetration of EVs, it is estimated that the demand for lithium, cobalt and graphite will increase by about 25 times, and the demand for rare-earth elements by 10 times (Fig. 3). These growth rates may be even higher if based on latest and more ambitious scenarios describing the uptake of EVs in 2030 and beyond.

There is also a high risk that materials strategic for the transition to low-carbon mobility will shift EU dependency from oil to raw material suppliers. The majority of lithium mines are under the control of Chinese companies, which poses concerns to the competitiveness of EU companies ${ }^{6}$. Another crucial material for batteries, cobalt, is also produced by just a few countries. In particular, more than half of the world's cobalt is currently mined (often illegally) by the Democratic Republic of the Congo (DRC) and it is likely that the situation will not change in the near future [25]. Since cobalt mining in the DRC has so often been linked to violence, the mineral has been dubbed the "blood diamonds of this decade".

For road transport to become truly sustainable in Europe, also these issues must be taken into account and the supply of critical materials should unlock new and more resource-efficient solutions. For example, used traction batteries can be removed from EVs to be remanufactured and reused again in new vehicles. Alternatively, used batteries can be repurposed for stationary energy-storage applications (e.g. in residential or office buildings) to reduce the costs of storing energy systems in buildings, especially those equipped with renewable energy plants, and used batteries can also be extracted from vehicles for material recycling.

Reused solutions (for batteries or other vehicle parts) will ensure a more efficient use of raw materials overall. Remanufacturing, in particular, already represents a resource-efficient practice for reusing mechanic and mechatronic components. The 30 million spare parts remanufactured for cars and trucks each year represent more than 50\% of spare parts overall, and have a market value of about 12 billion $€[2]$. In future, more remanufacturing processes are expected for electronic components, batteries and permanent magnet motors. These parts can be directly reused provided that design-for-disassembly strategies are adopted to facilitate their extraction from end of life vehicles.

Overall, if vehicles and systems are well designed, such resource-efficient solutions are likely to partially reduce pressure on the supply of raw materials. Currently, this potential is only being exploited in part as these strategies are only beginning to emerge in the EU. Finally, reuse and recycling practices will have to be synergistically optimised

\footnotetext{
${ }^{6}$ https://d1 owejb4br3112.cloudfront.net/publications/executivebriefing/the-european-battery-alliance.pdf
} 
since reused components will have to be recycled when their performance becomes too low also for secondary applications, such as stationary energy storage. In the coming decades, it is expected that recycling processes for batteries will rapidly develop in order to optimise the recovery of raw materials (including fractions currently being lost) and the production of high-quality secondary raw materials [26].

Also this example shows how changes in the transport system may have consequences going far beyond transport itself. In addition it shows that the potential of new technologies can actually materialize only if proper governance is put in place. The synergy among remanufacturing, reusing and recycling will not spontaneously emerge and will need the support of policy to really put the system on the right track.

\section{Living Labs to address transport complexity}

The two examples provided in this paper show the importance, for systems so intertwined with other systems of our society, like the transportation system, to adopt a holistic approach when trying to understand the implications of policies and technologies applied to them [3]. This is unfortunately easier said than done. Capturing the complexity of intertwined social system at a level useful for policy assessment is not a trivial task. The use of articulated modelling tools for this purpose has attracted several criticisms in the past [27]. The impossibility to keep under control all model components and the reliance on a high number of parameters of difficult estimation has raised concerns to the fact that they can be instrumentally tuned to achieve any result and justify any political decision.

An alternative approach that can be used to understand the effect of social systems complexity is to experiment in real life in a number of pilot test-beds or living labs.

Living labs are "user-centred, open innovation ecosystems based on systematic user co-creation approach, integrating research and innovation processes in real life communities and settings" [28]. To support policy development the living lab concept can be applied in two ways. In "passive" living labs, a certain policy or technology is introduced in a pilot context without the engagement of citizens. The social experiment lasts the time needed to see the effect of the new policy. In this way it is possible to anticipate the possible problems that it may induce and keep the proper countermeasures for larger scale applications. In "active" living labs, instead, citizens are engaged since the early stages of the innovation development and take an active role in the collaborative development of the new solutions together with other stakeholders from the public sector, academia and industry.

In spite of the difficulties of public engagement practices, active living labs can be significantly more effective than passive ones. Involving citizens in the innovation process not only helps tailoring a specific policy to the needs of the local community but allows identifying much quicker the possible causes of success or failure of a certain idea.

As already mentioned in the introduction, in the case of future mobility, policy sees a prominent role of technology to address transport externalities. But what happens if people reject the idea? In an era in which the sense of distrust and repulsion with regard to public institutions is becoming so widespread also in the most advanced democracies, can we run the risk not to involve citizens in the development of the new society? Just to understand the relevance of the problem, a recent Eurobarometer survey involving almost 30000 European citizens has for showed that people are not ready for a transition to a connected and automated mobility for a lack of trust and perception regarding the added value of these technologies on their daily life [29]. More specifically, when asked whether they would feel comfortable travelling in a fully automated vehicle, most of respondents gave a fairly negative reply especially in the case of travelling without human supervision (Fig. 4).

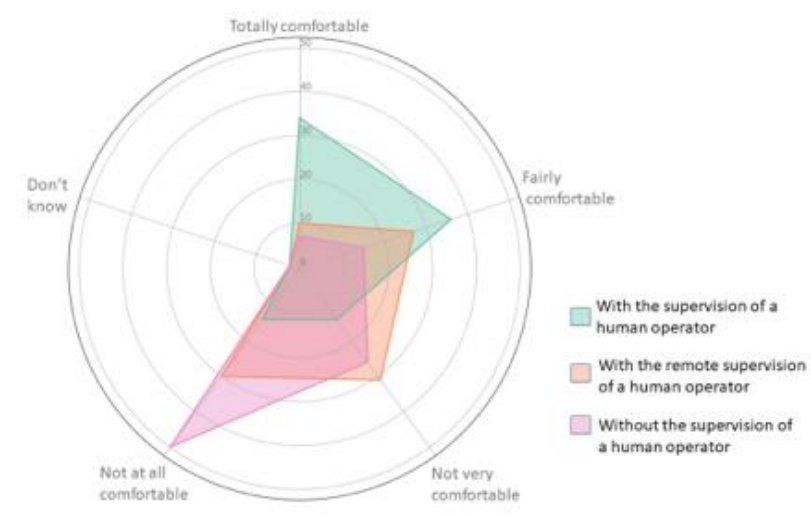

Fig. 4. Responses to the question "Would you feel comfortable travelling in a fully automated vehicle..?" in the Eurobarometer Survey 496 [29]

Establishing a network of 'European living-labs' is one way to create the right environment in which innovative mobility solutions are tested and rolled out with the direct involvement of people. A network of living-labs can be used to support the policy process throughout its whole life cycle and living labs can operate in a passive or active way depending on the nature of the policy to be tested. The Joint Research Centre of the European Commission has started his research on the use of the living-labs for policy support by creating its own one applied to urban ecosystems within its sites and by engaging with associations of living labs operating in the same field (e.g. ENoLL, EIT Urban Mobility Kic, etc.). The ambition is to create a concrete framework in which several European living labs can provide a bottom up support to EU policies.

\section{Conclusions}

The present paper has discussed some of the possible implications of automation, connectivity, electrification and "sharification" of road transport. The theoretical considerations, supported by the first evidences from real world applications showed that without properly governing the introduction and use of new technologies, they could even further exacerbate some of transport externalities.

In particular, any future policy should carefully take into account the implication of transport complexity, namely the relationship between the transport system and the other systems characterizing our society. In particular, new technologies risk to make the car, privately owned or consumed as a service, even more attractive and therefore even more at the center of the mobility landscape, with consequent 
risks of increased energy demand and the depletion of critical raw materials, among the others.

Since transport complexity make it hard to reliably anticipate the possible implications of many transport policies, the paper also suggested the need to experiment in real life through the creation of a constellation of European "living labs", where new technologies can be introduced with the direct engagement of citizens.
By assessing the outcomes of these real-life experimentations, inference can be drawn on the impact of new policies and technologies as well as on the conditions needed for their positive impact for the society.

\section{Acknowledgements}

The content of this paper is based on the research carried out by the JRC colleagues working in the Sustainable Transport Unit and by the authors of the JRC report on the Future of Road Transport.

\section{Nomenclature}
BEV Battery Electric Vehicle
CAV Connected and Automated Vehicle
DRC Democratic Rebublic of Congo
ENoLL European Network of Living Labs
EU European Union
FCEV Fuel cell electric vehicle
GDP Gross Domestic Product
ICEV Internal Cobustion Engine Vehicle
LCA Life Cycle Assessment
LCV Light Commercial Vehicle
PHEV Plug-in Hybrid Electric Vehicle
NEDC New European Driving Cycle
SDG Sustainable Development Goal
V2X Vehicle to anything communication
WLTP Worldwide harmonized Light-duty vehicles Test Procedure

\section{Bibliography}

[1] VESPE, M., MINORA, U., IACUS, S. et al. Restrictions in Italy using Mobile Network Operator Data. EUR 30630 EN. Publications Office of the European Union. Luxembourg 2021. https://doi.org/10.2760/241286, JRC124130

[2] ALONSO RAPOSO, M., CIUFFO, B., ARDENTE, F. et al. The future of road transport - implications of automated, connected, low-carbon and shared mobility. EUR 29748 EN. Publications Office of the European Union. Luxembourg 2019. https://doi.org/10.2760/9247, JRC116644

[3] CASCETTA, E. Transportation Systems Analysis, Models and Applications. Springer 2009.

https://doi.org/10.1007/978-0-387-75857-2

[4] TSAKALIDIS, A., VAN BALEN, M., GKOUMAS, K. et al. Research and innovation in transport electrification in Europe. EUR 30387 EN. Publications Office of the European Union. Luxembourg 2020. JRC120533.

https://doi.org/10.2760/675535

[5] European Parliament. $\mathrm{CO}_{2}$ emissions from cars: facts and figures (infographics). 2019.

https://www.europarl.europa.eu/news/en/headlines/society/2 0190313STO31218/co2-emissions-from-cars-facts-andfigures-infographics (accessed 5.08.2021)

[6] EUROPEAN COMMISSION. Regulation (EC) no 443/2009 of the European Parliament and of the Council of 23 April 2009 setting emission performance standards for new passenger cars as part of the Community's integrated approach to reduce $\mathrm{CO}_{2}$ emissions from light-duty vehicles. Official Journal of the European Commission. L 140, 5.6.2009, 1-15.

[7] FONTARAS, G., ZACHAROF, N.-G., CIUFFO, B. Fuel consumption and $\mathrm{CO}_{2}$ emissions from passenger cars in Europe - laboratory versus real-world emissions. Progress in Energy and Combustion Science. 2017, 60, 97-131.

https://doi.org/10.1016/j.pecs.2016.12.004

[8] EUROPEAN COMMISSION. Regulation (EC) 2017/1151 of 1 June 2017 supplementing Regulation (EC) No 715/2007 of the European Parliament and of the Council on typeapproval of motor vehicles with respect to emissions from light passenger and commercial vehicles (Euro 5 and Euro 6) and on access to vehicle repair and maintenance information, amending Directive 2007/46/EC of the European Parliament and of the Council, Commission Regulation (EC)
No 692/2008 and Commission Regulation (EU) No 1230/2012 and repealing Commission Regulation (EC) No 692/2008. Official Journal of the European Union. L 175, 2017, 1-643.

[9] PAVlOVIC, J., CIUFFO, B., FONTARAS, G. et al. How much difference in type-approval $\mathrm{CO}_{2}$ emissions from passenger cars in Europe can be expected from changing to the new test procedure (NEDC vs. WLTP)? Transportation Research Part A: Policy and Practice. 2018, 111.

https://doi.org/10.1016/j.tra.2018.02.002

[10] WEISS, M., BONNEL, P., HUMMEL, R. et al. On-road emissions of light-duty vehicles in Europe. Environmental Science \& Technology. 2011, 45(19), 8575-8581. JRC65638. https://doi.org/10.1021/es2008424

[11] WEISS M., BONNEL P., HUMMEL, R. et al. A complementary emissions test for light-duty vehicles: Assessing the technical feasibility of candidate procedures. EUR 25572. Luxembourg (Luxembourg): Publications Office of the European Union; 2013. JRC75998. https://doi.org/10.2790/66783

[12] VALVERDE MORALES, V., CLAIROTTE, M., BONNEL, P. et al. Joint Research Centre 2018 light-duty vehicles emissions testing, EUR 29897 EN, Publications Office of the European Union, Luxembourg 2019. JRC117625. https://doi.org/10.2760/155802,

[13] KERAMIDAS, K., TCHUNG-MING, S., DIAZVAZQUEZ, A.R. et al. Global energy and climate outlook 2018: Sectoral mitigation options towards a low-emissions economy - Global context to the EU strategy for long-term greenhouse gas emissions reduction. EUR $29462 \mathrm{EN}$, Publications Office of the European Union, Luxembourg 2018. JRC113446. https://doi.org/10.2760/67475

[14] HILL, N., AMARAL, S., MORGAN-PRICE, S. Determining the environmental impacts of conventional and alternatively fuelled vehicles through LCA. Final Report for the European Commission, DG Climate Action. 2020 Contract Ref. 34027703/2018/782375/ETU/CLIMA.C.4.

https://ec.europa.eu/clima/sites/default/files/transport/vehicl es/docs/2020_study_main_report_en.pdf (accessed on 5.08.2021). 
[15] HE, Y., MAKRIDIS, M., FONTARAS, G. et al. The energy impact of adaptive cruise control in real-world highway multiple-car-following scenarios. European Transport Research Review. 2020, 12.

https://doi.org/10.1186/s12544-020-00406-w

[16] CIUFFO, B., MATTAS, K., MAKRIDIS, K. et al. Requiem on the positive effects of commercial adaptive cruise control on motorway traffic and recommendations for future automated driving systems. Transportation Research Part C: Emerging Technologies. 2021, 130, 103305. https://doi.org/10.1016/j.trc.2021.103305

[17] FIORI, C., ARCIDIACONO, V., FONTARAS, G. et al. The effect of an electrified mobility on the relationship between traffic conditions and energy consumption. Transportation Research Part D: Transport and Environment. 2019, 67, 275-290. https://doi.org/10.1016/j.trd.2018.11.018

[18] GAWRON, J.H., KEOLEIAN, G.A., DE KLEINE, R.D. et al. Life cycle assessment of connected and automated vehicles: sensing and computing subsystem and vehicle level effects. Environmental Science \& Technology. 2018, 52(5), 3249-3256. https://doi.org/10.1021/acs.est.7b04576

[19] TAIEBAT, M., STOLPER, S., XU, M. Forecasting the impact of connected and automated vehicles on energy use: a microeconomic study of induced travel and energy rebound. Applied Energy. 2019, 247, 297-308. https://doi.org/10.1016/j.apenergy.2019.03.174

[20] AURAMBOUT, J.P., GKOUMAS, K., CIUFFO, B. Lastmile delivery by drones: an estimation of viable market potential and access to citizens across European cities. European Transport Research Review. 2019, 11, 1-21. https://doi.org/10.1186/s12544-019-0368-2

[21] FIGLIOZZI, M.A. Lifecycle modeling and assessment of unmanned aerial vehicles (Drones) $\mathrm{CO}_{2 \mathrm{e}}$ emissions. Transportation Research Part D: Transport and Environment. 2017, 57, 251-261. https://doi.org/10.1016/j.trd.2017.09.011

[22] Agora Verkehrswende. On autopilot to a more efficient future? How data processing by connected and autonomous vehicles will impact energy consumption. 2021.
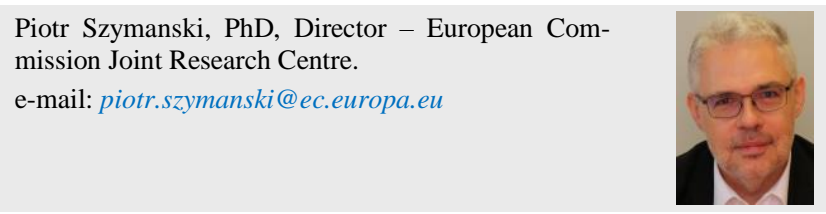

Georgios Fontaras, PhD - European Commission Joint Research Centre.

e-mail: georgios.fontaras@ec.europa.eu

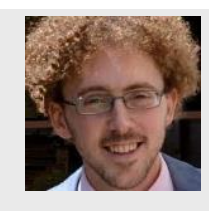

Giorgio Martini, PhD - European Commission Joint Research Centre.

e-mail: giorgio.martini@ec.europa.eu https://www.agora-verkehrswende.de/en/publications/onautopilot-to-a-more-efficient-future/ (accessed on 5.08.2021).

[23] BLAGOEVA, D.T., ALVES DIAS, P., MARMIER, A. et al. Assessment of potential bottlenecks along the materials supply chain for the future deployment of low-carbon energy and transport technologies in the EU, wind power, photovoltaic and electric vehicles technologies, time frame: 20152030. EUR 28192 EN. Publications Office of the European Union. Luxembourg 2016. JRC103778. https://doi.org/10.2790/08169.

[24] EUROPEAN COMMISSION. Raw materials scoreboard 2018. European innovation partnership on raw materials. Publications Office of the European Union. Luxembourg 2018. https://doi.org/10.2873/567799

[25] ALVES DIAS, P., BLAGOEVA, D., PAVEL, C. et al. Cobalt: demand-supply balances in the transition to electric mobility. EUR 29381 EN. Publications Office of the European Union. JRC112285. Luxembourg 2018. https://doi.org/10.2760/97710

[26] MATHIEUX, F., ARDENTE, F., BOBBA, S. et al. Critical raw materials and the circular economy - background report. EUR 28832 EN. Publications Office of the European Union. JRC108710. Luxembourg 2017. https://doi.org/10.2760/378123

[27] SALTELLI, A., FUNTOVICZ, S. When all models are wrong. Issues in Science and Technology. 2014, 30(2), 7985. https://issues.org/andrea/ (accessed on 5.08.2021).

[28] European Network of Living Labs. What are Living Labs. Eur. Netw. Living Labs. 2020. https://enoll.org/about-us/ (accessed 6.08.2021).

[29] EUROPEAN COMMISSION. Special Eurobarometer survey on expectations and concerns of connected and automated riving.

https://europa.eu/eurobarometer/surveys/detail/2231 (accessed 24.08.2021).

Biagio Ciuffo, PhD - European Commission Joint Research Centre.

e-mail: biagio.ciuffo@ec.europa.eu

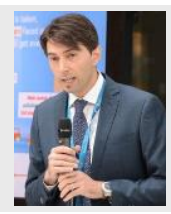

Ferenc Pekar, MSc - European Commission Joint Research Centre.

e-mail:ferenc.pekar@ec.europa.eu

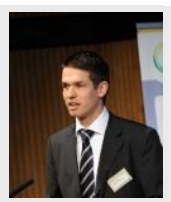

